It has been decided in exceptional cases, where an applicant's public and definite record gives full guarantee of his fitness for ophthalmic practice, that the certificate of the Board should be granted without such an examination as would be necessary for those whose professional record had yet largely to be made. That the activities of the Board have already awakened an important interest in the subject of training for ophthalmic practice is shown by the number of letters, asking for details of the examinations or of the necessary course of study, received from individuals and from institutions.

During the term covered by the Report, Dr. John E. Weeks has succeeded Dr. William $\mathrm{H}$. Wilder as representing the American Ophthalmological Society, while Drs. E. C. Ellett and F. C. Todd, representatives of the Section on Ophthalmology of the American Medical Association and the American Academy of Ophthalmology and Oto-Laryngology, "were chosen to succeed themselves," their term of office having expired. The personnel of the Board during the year dealt with by the Report was as follows : Chairman, Edward Jackson; Vice-Chairman, Myles Standish ; Secretary, F. C. Todd; Committee on Preliminary Requirements, Myles Standish, William H. Wilder, and F. C. Todd; Committee on Examinations, Hiram Woods, Walter B. Lancaster, and Wendell Reber; Committee on Finance, Edward Jackson, E. C. Ellett, A. Duane.

An interesting question that had engaged the attention of the Board was the need of special examinations for applicants for Fellowship in the American College of Surgeons, who claimed eligibility upon the ground of being engaged in eye work, and the difficulties experienced by the College in giving such applicants proper examinations. The Board entered into negotiations with the authorities of the College, who agreed to leave the Board in control of all ophthalmic examinations, and to defray the expenses of the work. The urgency of the question may be gathered from the bald statement that there are now several hundred applicants awaiting examinations in ophthalmology to determine their fitness for Fellowship in the College.

\title{
The new American Ophthalmic Journal
}

As our readers are already aware, a new journal of ophthalmology has been projected in America for some little time. 'There exist many good reasons why such a venture should be undertaken at the present juncture, but into these we need not enter here. The name of the journal has not yet been announced, but it is to be published monthly, and the first number will appear in January, 
1918. It will be formed by the combination of the Annals of Obhthalmology, the Ophthalmic Record, Obhthalmology, the Ophthalmic Year Book, and Ophthalmic Literature. The omission of the names of certain periodicals will be noted, but there are reasons for believing that at least one of them will enter the combination. The newcomer will be owned by a company, the shares in which will be largely held by ophthalmic surgeons, and in order to prevent the stock from becoming of speculative value, it has been arranged that it shall always remain in the hands of ophthalmologists. It is believed that "the new journal will probably start with the largest list of subscribers of any ophthalmic journal published in the world," and it is hoped that "it will offer its contributors the best presentation of their papers, both as to paper, presswork, proof reading, and illustrations that it is possible to secure in America" (Ophthalmic Literature, July, 1917).

\section{The Children of Blinded Soldiers}

That indefatigable worker in the interests of the blind, Sir Arthur Pearson, has issued an appeal for providing a fund whereby every child born to a blinded soldier after his disablement shall be allowed 5s. a week until the age of sixteen. It is estimated that the total sum required for this purpose may amount to $£ 250,000$.

\section{The Eyesight of Colliery Officials}

The Home Secretary has drawn the attention of medical practitioners to a particular section of the Coal Mines Act, 1911, which requires that certified firemen, examiners, or deputies must obtain every five years a new certificate that their eyesight is adequate to enable them to conduct proper tests for inflammable gas, and that their hearing enables them to perform their duties efficiently. Such certificate may be obtained from an authority approved by the Secretary of State or from a medical practitioner. The new certificate must be made out in the prescribed form (Mines and Quarries Form, No. 73), and can only be granted after applying certain specified tests.

\section{War Nephritis}

In Sundell and Nankivell's article in the Lancet of September 15,1917 , the eye changes in war nephritis (35 consecutive cases) are thus reported by Capt. R: Graham Brown :-

"The fundus was normal in 29, while in 6 slight blurring of a 